\title{
Functional Impairment as a Risk Factor for Urinary Incontinence Among Older Americans
}

\author{
Kristi Rahrig Jenkins ${ }^{1 *}$ and Nancy H. Fultz ${ }^{2}$ \\ ${ }^{1}$ University of Michigan, Institute for Social Research, Ann Arbor, Michigan \\ ${ }^{2}$ University of Michigan, Institute for Research on Women and Gender, Ann Arbor, Michigan
}

\begin{abstract}
Aims: Using a large nationally representative sample of older Americans we investigate four domains of functional impairment as possible risk factors for the subsequent development of urinary incontinence (UI) symptoms. Methods: Data from three waves $(1993,1995,1998)$ of the Asset and Health Dynamics among the Oldest Old (AHEAD) survey were used to model the effects of functional impairment on the onset of UI symptoms. Results: A greater number of serious chronic conditions and functional impairment in the lower body mobility domain increased the odds of the onset of mild UI (vs. remaining continent). Factors that contributed to greater odds of the onset of severe UI (vs. remaining continent) were older age, being represented by a proxy respondent, and functional impairment in the strength domain. Conclusions: Understanding the possible relationship between functional impairment and UI is an important step toward developing appropriate interventions for the prevention, treatment, or management of urine loss. Neurourol. Urodynam. 24:51-55, 2005. (C) 2004 Wiley-Liss, Inc.
\end{abstract}

Key words: epidemiology; older adults; physical function; survey research

\section{INTRODUCTION}

Despite growing recognition of the negative consequences of urinary incontinence (UI), such as increased need for informal [Langa et al., 2002] and formal [Thom et al., 1997] health care, relatively little is known about risk factors for the onset of symptoms [Hunskaar et al., 2003]. This reflects both the multifactorial nature of UI and the difficulty of determining the causal and temporal ordering among variables with which it correlates. Studies utilizing longitudinal data and implementing statistical controls to differentiate between alternative hypotheses could advance the identification of risk factors for UI [Hunskaar et al., 2003]. Unfortunately, there has been a shortage of rigorous epidemiologic analyses in this area [Hunskaar et al., 2003]. For the present research, we use a large representative panel survey of older Americans to explore specific domains of functional impairment as potential risk factors for UI. An association between UI and functional impairment, especially mobility impairment, has been demonstrated in several studies [Ouslander et al., 1987; Diokno et al., 1990; McGrother et al., 1990; Maggi et al., 2001] but most have been based on cross-sectional data and/or smaller clinical samples that may not generalize to the larger population.

Functional impairment is the inability to perform various physical tasks and activities required for independent living. Whereas such impairment is often assumed to cause or aggravate UI [Cheater and Castleden, 2000] by hampering the use of the toilet, it is equally plausible to suggest that UI could contribute to functional impairment. This might occur through the increased risk of falls associated with UI [Brown et al., 2000] or through incontinent women's lower likelihood of engaging in physical exercise [Brown and Miller, 2001]. Moreover, certain pre-existing disease processes or medical conditions could lead to both UI and functional impairment through independent pathways. For example, functional limitation and UI are common sequelae of stroke [National Institute of Neurological Disorders and Stroke, 2003], suggesting that, in some cases, the association between functional impairment and UI may be spurious. These three causal models are not mutually exclusive, and all may be involved in the disablement process.

This study focuses on the first of the models, hypothesizing that functional impairment predicts subsequent UI symptoms among Americans. Using data from a longitudinal survey of a large national sample of people aged 70 and over, we investigate four dimensions of functional impairment (strength

An earlier version of this study was presented at the 2002 Gerontological Society of America Annual Meetings.

Grant sponsor: National Institute on Aging (to K.R.J.); Grant number: T32AG00221; Grant sponsor: National Institutes of Health (to N.H.F.) for HRS data collection; Grant number: K12 HD01438; Grant sponsor: National Institute on Aging; Grant number: U01-AG09740.

*Correspondence to: Kristi Rahrig Jenkins, Ph.D., University of Michigan, Institute for Social Research, 426 Thompson St., Room \# 2044, Ann Arbor, MI 48106. E-mail: Kristirj@isr.umich.edu

Received 8 July 2004; Accepted 3 October 2004

Published online 2 December 2004 in Wiley InterScience

(www.interscience.wiley.com)

DOI 10.1002/nau.20089 
impairment, lower body mobility impairment, upper body mobility impairment, and impairment in performing activities of daily living) as risk factors for UI. We hypothesize that functionally impaired older adults are more likely to experience the onset of incontinence symptoms than are those who are not functionally impaired. We further hypothesize that strength impairment and lower body mobility impairment will show the stronger effects because of their relevance to accessing and using the toilet.

Because UI can have a negative impact on quality of life [Wyman, 1999], identifying modifiable risk factors is critical. Understanding possible relationships that may link functional impairment with UI is an important step toward developing interventions to prevent the onset of urine loss and to promote recovery of urine control. It is only through an understanding of the processes that underlie an apparent association that we can target resources at those variables likely to lead to the best outcomes for patients and their families.

\section{METHODS}

\section{Data}

Data from three waves of the Asset and Health Dynamics Among the Oldest Old survey (AHEAD), 1993, 1995, and 1998, were used to examine the effect of functional impairment on the onset of UI symptoms. The AHEAD is a longitudinal study of a nationally representative sample of household residents who were aged 70 and older in 1993 (and their spouses). When respondents can no longer participate in an interview due to death or cognitive decline, proxy respondents are tapped for information. AHEAD respondents are followed once they enter a nursing home. However, since the AHEAD sample represents household residents, nursing home residents are given a weight of zero and, therefore, automatically excluded from any weighted analyses. The AHEAD is a component of the Health and Retirement Study (HRS), which is conducted at the University of Michigan with funding from the National Institute on Aging. Information about the study design and public use data products are available through the HRS website at http://hrsonline.isr.umich.edu. Data for the present analysis were restricted to the AHEAD cohort of age-eligible respondents who had valid responses on all measures and were continent in 1993 and 1995 (see the definition of continence below). The number of respondents meeting these criteria is 2838 .

\section{Measures}

Two questions were used to determine (in)continence status. At each year of data collection $(1993,1995,1998)$, respondents were first asked, "During the last 12 months, have you lost any urine beyond your control?" Those who reported urine loss were then asked, "On about how many days in the last month have you lost any urine?" In order to model the onset of incontinence symptoms, we limited the analyses to individuals who reported complete continence (i.e., no urine loss in at least the previous month) in both 1993 and 1995. This was done to minimize the influence of transient incontinence and/or measurement unreliability on the results. In 1998, respondents were classified as remaining continent (i.e., no urine loss in at least the previous month) or as experiencing the onset of mild incontinence (i.e., having lost urine less than or equal to 20 days in the last month) or severe incontinence (i.e., having lost urine greater than or equal to 21 days in the last month).

Functional impairment was assessed by constructing four summary measures from the 1995 data: strength impairment, upper body mobility impairment, lower body mobility impairment, and impairment in the ability to perform activities of daily living (ADLs). Distinguishing between various domains of functioning is important because the use of global measures of functioning may have a masking effect [Ferraro et al., 2002] on various health outcomes. Prior to this project, the lead author did a factor analysis and concluded that these four domains of impairment were the most appropriate for these analyses. Strength impairment was gauged via answers to four questions about difficulty sitting for $2 \mathrm{hr}$ or longer; stooping, kneeling, or crouching; getting up from a chair after sitting for long periods; and pulling or pushing large objects such as a living room chair. Upper body mobility impairment was gauged via answers to three questions about having difficulty lifting or carrying an object that weighs over 10 pounds (like a bag of groceries); picking up a dime from a table; and lifting arms above the shoulder level. Lower body mobility impairment was measured via answers to three questions about having difficulty walking several blocks, walking one block, and climbing one flight of stairs. ADL impairment was derived from answers to four questions about having difficulty dressing, bathing, eating, or getting out of bed.

The response categories for each component question ("yes," "no," or "can't do") were coded as yes/can't do = impaired vs. no = not impaired. If a respondent was coded as impaired for one or more of the components of a domain, he/ she was considered to be impaired for that domain. Only those who responded "no" to all difficulty questions in a given functional area were considered to have no impairment in that domain. Thus, each of the four impairment domains is represented by a dichotomous variable: impaired versus not impaired.

Standard socio-demographic controls (as measured in 1995) included age, gender, race (non-Hispanic African American, Latino, and non-Hispanic White), marital status, income, and education. Shaw et al. [2000] found that proxy respondents were reasonable substitutes for self-reports of physical functioning tasks but not as reliable for more instrumental activities of daily living measures, and also that there was less agreement between proxy and self-reports of assessing frequency of UI. For this reason, we included a dichotomous measure that flags proxy respondents $(=1)$ and self-reports 
$(=0)$. In addition, we included two measures of co-morbidity (also based on the 1995 data). An index of serious chronic conditions was constructed by counting the respondent's reports of physician-diagnosed high blood pressure, diabetes, cancer, chronic lung disease, heart problems, arthritis, or stroke (range: 0-7). Persistent or troublesome health problems were represented through a count of the respondent's experience with leg pain or leg cramps at night; persistent swelling in feet or ankles; shortness of breath while awake; persistent dizziness or lightheadedness; back pain or problems; persistent headaches; severe fatigue or exhaustion; persistent wheezing, coughing, or bringing up phlegm; or difficulty/burning when urinating (range: $0-9$ ).

\section{Analysis}

Descriptive and multivariate analyses were used to evaluate the relationship between the four domains of functional impairment and the onset of UI. Means for continuous variables and frequencies for categorical variables were used to describe these data. $t$-tests of proportions for categorical variables and $t$-tests of means for continuous variables were used to determine statistical significance for the descriptive characteristics. We then used polytomous logistic regression to estimate the odds of becoming mildly or severely incontinent (vs. remaining continent) as determined by functional impairment, health, and socio-demographic characteristics. Data were analyzed using IVEware software [Raghunathan et al., 2000] to account for the weighting and complex sample design of the AHEAD survey [Heeringa and Connor, 1995].

\section{RESULTS}

Table I describes the socioeconomic and demographic characteristics, health characteristics, and functional impairment status of continent, mildly incontinent, and severely incontinent older adults. Reviewing the socioeconomic and demographic characteristics, it is apparent that, compared to continent older adults, mild and severely incontinent adults are older ( 78.6 and 80.5 vs. 77.7 years of age), and have a smaller proportion of males (36.8 and 34.3 vs. 47.9 ). Mild and severely incontinent older adults also appear to be less healthy than continent older adults, based on the measures of serious conditions and persistent symptoms or problems. In terms of functional impairment, (in)continence status is shown to relate to all four domains of impairment. Among all domains of impairment, mild and severely incontinent older adults have a greater proportion of impairment.

Table II reviews the results of the polytomous logistic regression model of functional impairment as a risk factor for the onset of mild or severe UI. Having a greater number of serious chronic conditions ( $\mathrm{OR}=1.22 ; 95 \% \mathrm{CI}=1.02$, 1.45) and functional impairment in the lower body mobility domain $(\mathrm{OR}=1.56 ; 95 \% \mathrm{CI}=1.09,2.23)$ increases the odds

TABLE I. Descriptive Results of Socioeconomic and Demographic Controls, Health Characteristics, and Functional Impairment by Urinary Incontinence Status

\begin{tabular}{|c|c|c|c|}
\hline & $\begin{array}{l}\text { Continent } \\
(\mathrm{n}=2,572)\end{array}$ & $\begin{array}{l}\text { Mild incontinence } \\
\quad(\mathrm{n}=163)\end{array}$ & $\begin{array}{l}\text { Severe incontinence } \\
\qquad(\mathrm{n}=103)\end{array}$ \\
\hline \multicolumn{4}{|l|}{ Socioeconomic and demographic controls } \\
\hline Age (mean) & 77.7 & $78.6 *$ & $80.5 * * *$ \\
\hline Male (\%) & 47.9 & $36.8 * *$ & $34.3 *$ \\
\hline African American (\%) & 7.3 & 7.8 & 9.6 \\
\hline Latino $(\%)$ & 3.3 & 3.0 & 5.1 \\
\hline White (\%) & 89.5 & 89.1 & 85.3 \\
\hline Married (\%) & 57.7 & $48.8^{*}$ & 46.7 \\
\hline HH income (mean) & 32,775 & 30,149 & $19,880 * * *$ \\
\hline Education (mean) & 11.6 & 11.3 & $10.0 \% *$ \\
\hline Proxy respondent $(\%)$ & 12.0 & $16.4^{* * *}$ & $44.2^{* * * *}$ \\
\hline \multicolumn{4}{|l|}{ Health characteristics } \\
\hline Serious chronic conditions (mean) & 1.7 & $2.2^{* * *}$ & $2.0 *$ \\
\hline Persistent health problems (mean) & 1.3 & $2.0 \% * *$ & $2.0 * *$ \\
\hline \multicolumn{4}{|l|}{ Functional impairment } \\
\hline Strength impairment (\%) & 57.4 & $74.5^{* * * *}$ & $82.4 * * *$ \\
\hline Lower body mobility impairment (\%) & 31.5 & $53.7 * * *$ & $61.1 \%$ \\
\hline Upper body mobility impairment (\%) & 31.7 & $45.7 * *$ & $53.0 * * *$ \\
\hline ADL impairment $(\%)$ & 13.4 & $26.6^{* * * *}$ & $37.1 \% * \%$ \\
\hline
\end{tabular}

Data in this table are weighted and adjusted for the complex survey design. Incontinence status was measured in 1998; all other variables were measured in 1995. Source of data: Asset and Health Dynamics Among the Oldest Old. $\because P<0.05$.

$\because * P<0.01$

$\because * P P<0.001$. 
TABLE II. Polytomous Regression Model of the Onset of Urinary Incontinence by Socioeconomic and Demographic Controls, Health Characteristics, and Functional Impairment $(\mathbf{n}=\mathbf{2 8 3 8})$

\begin{tabular}{|c|c|c|}
\hline & $\begin{array}{l}\text { Mild incontinence vs. } \\
\text { continence }\end{array}$ & $\begin{array}{l}\text { Severe incontinence vs. } \\
\text { continence }\end{array}$ \\
\hline \multicolumn{3}{|l|}{ Socioeconomic and demographic controls } \\
\hline Age & $1.02(0.98-1.06)$ & $1.05 *(1.02-1.09)$ \\
\hline Male & $0.75(0.46-1.21)$ & $0.64(0.34-1.20)$ \\
\hline African American & $0.92(0.58-1.46)$ & $0.87(0.52-1.46)$ \\
\hline Latino & $0.85(0.30-2.41)$ & $0.79(0.28-2.20)$ \\
\hline Married & $0.95(0.63-1.45)$ & $1.07(0.59-1.94)$ \\
\hline HH Income & $0.96(0.80-1.15)$ & $0.97(0.84-1.11)$ \\
\hline Education & $1.02(0.96-1.09)$ & $0.95(0.90-1.01)$ \\
\hline Proxy Respondent Flag & $1.35(0.84-2.17)$ & $4.33 *(2.47-7.58)$ \\
\hline \multicolumn{3}{|l|}{ Health characteristics } \\
\hline Serious chronic conditions & $1.22 *(1.02-1.45)$ & $1.01(0.82-1.25)$ \\
\hline Persistent health problems & $1.10(0.96-1.26)$ & $1.09(0.95-1.26)$ \\
\hline \multicolumn{3}{|l|}{ Functional impairment } \\
\hline Strength impairment & $1.24(0.87-1.76)$ & $1.97 *(1.12-3.48)$ \\
\hline Lower body mobility impairment & $1.56 *(1.09-2.23)$ & $1.41(0.76-2.62)$ \\
\hline Upper body mobility impairment & $0.82(0.54-1.25)$ & $0.76(0.42-1.37)$ \\
\hline ADL impairment & $1.28(0.91-1.79)$ & $1.62(0.96-2.74)$ \\
\hline
\end{tabular}

Entries are odds ratios with $95 \%$ confidence intervals in parentheses. Data in this table are weighted and adjusted for the complex survey design. Incontinence status was measured in 1998; all other variables were measured in 1995.

"Indicates that it is statistically significant. Source of data: Asset and Health Dynamics Among the Oldest Old.

of the onset of mild UI (vs. remaining continent). The factors that contribute to greater odds of the onset of severe UI (vs. remaining continent) are older age $(\mathrm{OR}=1.05 ; 95 \% \mathrm{CI}=$ $1.02,1.09)$, being represented by a proxy respondent $(\mathrm{OR}=$ $4.33 ; 95 \% \mathrm{CI}=2.47,7.58)$ and functional impairment in the strength domain $(\mathrm{OR}=1.97 ; 95 \% \mathrm{CI}=1.12,3.48)$.

\section{DISCUSSION}

The hypothesis that particular domains of functional impairment predict subsequent UI was generally supported in this longitudinal analysis of a nationally representative sample of older Americans. We found that strength impairment and lower body mobility impairment are critical domains, although the pattern of effects for those two domains was inconsistent across levels of UI severity.

These results are important because they confirm prior functional impairment as a possible risk factor for the onset of UI symptoms. Similar findings were reported recently for a clinical sample: Palmer, Baumgarten, Langenberg, and Carson [Palmer et al., 2002] analyzed medical records for female hip fracture patients and found that the use of a wheel chair or device for walking and prefracture dependence on others for ambulation significantly increased the odds of becoming incontinent during hospitalization. These results expand upon past studies by examining the possible impact of various domains of functional impairment on UI in a population context.
Our results should be interpreted in the context of a few potential limitations of the study. First, the AHEAD data did not contain measures to characterize the type of incontinence symptoms or the quantity of urine lost per episode of incontinence. These are important dimensions for understanding UI. In particular, it is possible that the effects of the domains of impairment would differ for stress vs. urge symptoms. Second, the data are based on respondents' reports rather than on physical examination or medical records. In general, however, self-reported health data have been shown to provide useful and valid information, which would otherwise be unavailable for analysis [Colditz et al., 1986; Robinson et al., 1997; Fried et al., 2001]. Third, we may have omitted an important explanatory variable from the model, which could change the relationship between functional impairment and the onset of incontinence symptoms. For example, we could not consider the effect of other persistent urologic or urogynecologic conditions because they are not measured in the AHEAD questionnaire. Our socio-demographic and health controls are fairly comprehensive, however, and are likely to "capture" the variance explained by other factors (e.g., health enhancing or damaging behaviors) that may relate to both functional impairment and UI.

Despite these limitations, this research provides important evidence among a large nationally representative sample of older Americans that older adults who are functionally impaired in certain domains may be predisposed to develop UI symptoms. Because little is currently known about the 
prevention of UI in older adults, it is important to focus intervention efforts on variables that predict its onset [Palmer, 2002]. Overall, incontinence is complex condition in a dynamic environment. Health care providers must be alert for opportunities to prevent, ameliorate, or improve [Schnelle et al., 1995] functional impairment among patients as a means of maintaining continence and quality of life. Among older adults who are currently functionally impaired, encouraging the use of assistive devices (e.g., walkers, canes, grab bars, etc) that aid in toileting may also contribute to positive outcomes.

\section{ACKNOWLEDGMENTS}

The research was supported, in part, by a post-doctoral fellowship from the National Institute on Aging and the Building Interdisciplinary Research Careers in Women's Health (BIRCWH) career development program of the National Institutes of Health. Health and Retirement Study data collection and provision is funded by a grant from the National Institute on Aging. The authors acknowledge the contributions made by the late A. Regula Herzog, $\mathrm{PhD}$, who was involved in planning this study. Special thanks are also given to Kenneth Langa, MD, PhD, Truls Østbye, MD, and Janis Miller, PhD for their helpful comments on an earlier version of this manuscript.

\section{REFERENCES}

Brown W, Miller Y.Too wet to exercise? Leaking urine as a barrier to physical activity in women. J Sci Med Sport 2001;4:373-8.

Brown J, Vittinghoff E, Wyman J, et al. Urinary incontinence: Does it increase risk for falls and fractures? J Am Geriatr Soc 2000;48:721-5.

Cheater F, Castleden C. Epidemiology and classification of urinary incontinence. Bailliere’s Best Practice \& Research. Baillieres Best Pract Res Clin Obstet Gynaecol 2000;14:183-205.

Colditz A, Martin P, Stampfer M, et al. Validation of questionnaire information on risk factors and disease outcomes in a prospective cohort study of women. Am J Epidemiol 1986;123:894-900.

Diokno A, Brock B, Herzog A, et al. Medical correlates of urinary incontinence in the elderly. Urology 1990;36:129-38.
Ferraro K, Su Y, Gretebeck R, et al. Body mass index and disability in adulthood: A 20-year panel study. Am J Public Health 2002;92:834-40.

Fried L, Young Y, Rubin G, et al. WHAS II Collaborative Research Group. Self-reported preclinical disability identifies older women with early declines in performance and early disease. J Clin Epidemiol 2001;54:889-901.

Heeringa G, Connor J. 1995. Technical Description of the Health and Retirement Study Sample Design. Online version. Originally published as HRS/ AHEAD Documentation Report DR-002.

Hunskaar S, Burgio K, Diokno A, et al. Epidemiology and natural history of urinary incontinence in women. Urology 2003;62:16-23.

Langa K, Fultz H, Saint S, et al. Informal caregiving time and costs for urinary incontinence in older individuals in the United States. J Am Geriatr Soc 2002;50:733-7.

Maggi S, Minicuci N, Langlois J, et al. Prevalence rate of urinary incontinence in community-dwelling elderly individuals: The Veneto Study. J Gerontol 2001;56:M14-8.

McGrother C, Jagger C, Clarke M, et al. Handicaps associated with incontinence: Implications for management. J Epidemiol Community Health 1990;44:246-8.

National Institute of Neurological Disorders and Stroke. 2003. http://www. ninds.nih.gov

Ouslander J, Morishitta L, Blaustein J, et al. Clinical, functional, and psychosocial characteristics of an incontinent nursing home population.J Gerontol 1987;42:631-7.

Palmer M. Primary prevention research on incontinence in older adults. West J Nurs Res 2002;24:390-405.

Palmer M, Baumgarten M, Langenberg P, et al. Risk factors for hospitalacquired incontinence in elderly female hip fracture patients. J Gerontol 2002;57:M672-7.

Raghunathan T, Solenberger P, Van Hoewyk J. 2000. IVEware: Imputation and variance estimation software installation instructions and user guide. The University of Michigan. Downloaded at: http://www.isr.umich.edu/ src/smp/ive/.

Robinson J, Young T, Roos L, et al. Estimating the burden of disease: Comparing administrative data and self-reports. Med Care 1997;35:932-47.

Schnelle JF, MacRae PG, Ouslander JG, Simmons SF, Nitta M. Functional incidental training, mobility performance, and incontinence care with nursing home residents. J Am Geriatr Soc 1995;43:1356-62.

Shaw S, McColl E, Bond S. Functional abilities and continence: The use of proxy respondents in research involving older people. Qual Life Res 2000; 9:1117-26.

Thom D, Haan M, Van Den Eden S. Medically recognized urinary incontinence and risks of hospitalization, nursing home admission and mortality. Age Ageing 1997;26:367-74.

Wyman J. Quality of life of older adults with urinary incontinence. J Am Geriatr Soc 1999;46:778-9. 